\title{
ENTRE BAYONETAS Y MUSAS
}

\author{
Carolina Cáceres Delgadillo* \\ Universidad Santo Tomás
}

\section{Aproximación a la vida y obra de Andrés Bello}

Andrés Bello fue uno de esos grandes genios que parió América en los albores de su emancipación. Nació en Caracas (1781) cuando apenas se comenzaba a cultivar en las mentes de los héroes americanos el germen de la revolución y el cambio social, cuando el hombre aún estaba dispuesto a entregar su vida por un ideal. Sin embargo, Bello no tuvo necesidad de hacerlo, porque sus ideas traspasaban cualquier campo de batalla, cualquier muerte con fusil. Se le puede definir como un espíritu sensible, que amaba los cambios, pero no los propiciados con las armas, sino los que provenían del corazón.

El medio ambiente en el que Bello triunfa es la sociedad colonial, inserta en un paisaje tropical exótico que ejerció en él una atracción inigualable. Esto nos hace recordar las palabras de George Luckacs: "toda conmoción histórica y social crea un hombre nuevo"; y es precisamente esa conmoción hispanoamericana (del paso de la Colonia a la Repúbli- ca) la que revistió con elementos novedosos la obra de Bello.

Visto a la luz de la tipología planteada por Gracia y Jasick en su introducción al problema de una filosofía latinoamericana, podemos ubicar la postura de Bello dentro de la perspectiva culturalista según la cual los elementos espacio-temporales son indispensables en la construcción de una cultura nueva. El punto de si hay o no verdades universales y absolutas con respecto a la filosofía en la obra de Bello nunca quedó claro. Algunas veces trabajó temas tradicionales, en otras se dejó llevar por la moda (teoría del conocimiento, ética, las nuevas ideologías, etc.).

A muy temprana edad, Bello tuvo que decidir entre el camino de las armas (tomado por casi todos sus contemporáneos) y el de la filosofía y la literatura, y escogió el segundo. Cuando regresa a América, se encuentra con el resultado devastador que dejó el camino que él veinte años antes rechazara. Durante las primeras décadas de la independencia fracasó la organización de las repúblicas, y triunfó, consecuentemente, la oligarquía conser-

\footnotetext{
* Estudiante de séptimo semestre, Facultad de Filosofía, Universidad Santo Tomás, Bogotá.
} 
vadora que había surgido como una solución al problema de la anarquía promovida por los caudillos militares y la falta de una conciencia ideológica realista. Tal vez excitado por esa situación catastrófica, producto de la falta de bases sólidas y comunes, es que Bello comienza a trabajar por las juventudes, sembrando en ellas el deseo de una lucha, ya no armamentista, sino intelectual, por medio de una literatura inspirada en la tierra, en el cultivo, en el ideal de una nación americana, como único camino para la libertad:

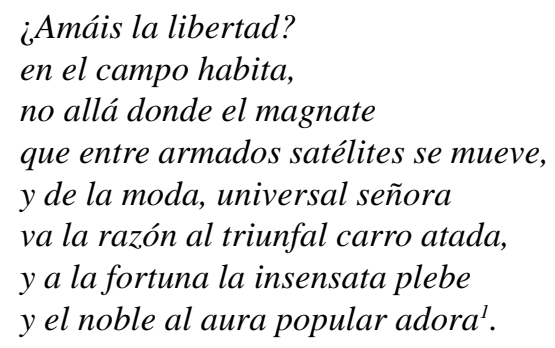

La delgada línea que separa la filosofía de la literatura fue transitada por Bello sin mayores tropiezos. Sin embargo, para los que estudian su obra, esa falta de delimitación significa desechar alguno de estos dos elementos, haciendo prácticamente imposible la unidad formal del análisis. Algunos, como José Gaos, Luis Recasens o Isaías García, consideran que es en el campo filosófico donde reside el verdadero sentido de la obra de Bello; otros, siendo lingüistas o literatos, consideran que el valor está dentro del campo propio de su objeto de estudio, y sólo se preocupan por hallar el tipo de métrica que manejaba Bello en sus poemas. No obstante, debemos tener en cuenta que el pensamiento latinoamericano desde siempre ha tomado como punto de partida una singular preocupación por lo estético, que se manifiesta tanto en el tema como en la forma de los escritos. Carlos Fuentes nos da una ex- plicación clara de por qué los pensadores latinoamericanos tienen como objeto formal el arte y no un método sistemático que conduzca sus estudios hacia una filosofía "universalmente válida”:

La historia de España, la historia de la América española ha sido lo que ha sido, su arte ha sido lo que la historia ha negado a España (a Latinoamérica en este caso), el arte da vida a lo que la historia ha asesinado, el arte da voz a lo que la historia ha negado, silenciado o perseguido. El arte rescata la verdad de manos de las mentiras de la historia"2.

La bifurcación del sendero se hace evidente, pero al mismo tiempo se maneja en la oscuridad una lucha entre el ser y el desear. El problema en este caso sería: ¿realmente queremos entrar en la esfera de las verdades universalmente válidas?, ¿o simplemente queremos construir una identidad a partir de nuestros problemas y nuestras necesidades, dándoles respuestas y alivio con nuestra propia voz y nuestro propio sentir latinoamericano? Partiendo desde aquí podemos afirmar que es en la obra poética donde realmente Bello plantea y desarrolla un punto de vista original y novedoso con respecto al problema de la filosofía y de la identidad latinoamericana, ya que su único texto filosófico, titulado "La filosofía del entendimiento", consiste en una serie de imitaciones nebulosas de los clásicos y, en el mejor de los casos, de los temas que estaban de moda por esa época en Europa.

Con respecto a las influencias en el pensamiento filosófico de Bello, Luis Recasens dice: "El pensamiento filosófico de Bello muestra algunos influjos del empirismo de Locke y del sensualismo de Condillac; así

\footnotetext{
“Agricultura de la zona tórrida”, vs. 148 -154.

2 FUENTES, Carlos. Cervantes o la crítica de la lectura. México: F.C.E., p. 82.
} 
como también, huellas del idealismo de Berkeley"3. No es de extrañar que la corriente que más influyó en él haya sido el empirismo inglés, no sólo porque vivió durante más de veinte años en Londres, sino también porque su formación universitaria estuvo bajo la tutela del "escotismo", que lo inclinaba ya hacia el empirismo ${ }^{4}$.

Bello resultó ser uno de aquellos filósofos de nuestra América que manejó esa extraña tendencia a exponer ciertas verdades repentinamente olvidadas, además de ser continuador tardío de algunos enunciados ya superados, esto tal vez por su larga estadía en Europa. Al respecto, afirma José Perdomo García que el desarrollo de la obra filosófica de Bello se caracteriza por el asincronismo. En conclusión, Bello en su filosofía maneja elementos tradicionales que combina casi de manera infantil con una serie de sugestiones (eso sí, muy nuevas), lo que nos permite observar que sus ideas estaban en perfecta concordancia con la situación general del pensamiento europeo, sin aportar nada nuevo en el campo filosófico desde una perspectiva latinoamericana.

No podemos negar que la obra filosófica de Bello cuenta con una fuerza original que va mas allá de las fuentes que lo inspiran. José Gaos afirma al respecto: “...si Bello hubiera sido escocés ó francés, su nombre estaría con las historias de la filosofía, al lado y en plan de igualdad con Stewart, Brown y Cousin”. Pero las circunstancias, o tal vez el destino, trazan caminos inesperados, y su esfuerzo por entrar en la historia como un filósofo "de lo nuestro” reconocido en el Viejo Mundo, fue infructuoso. Irónicamente, su obra poética, la que veía como una pasión más que como un camino para lograr lo que quería, es en la que realmente comenzó a bosquejar el panorama de la cultura latinoamericana: un paisaje poco alentador para el filósofo, pero lleno de gloria para el artista.

\section{Germen nacionalista en la poesía de Andrés Bello}

Sólo desde el regreso de Bello a América se puede hablar de las primeras promociones de intelectuales en el continente después del periodo de la independencia. Con Bello se comienza a cultivar una literatura nueva de orden académico, con temas netamente nacionalistas y políticos, que corresponde al nacimiento de una conciencia dinámica en la clase media burguesa. Es el caso de José Victorino Lastarria, quien, basado en las enseñanzas de Bello, funda en 1842 la "Sociedad literaria” y pronuncia en su inauguración un discurso en el que hallamos el siguiente fragmento:

...nuestra literatura debe sernos exclusivamente propia, debe ser enteramente nacional. Hay una literatura que nos legó España, con su religión divina, con sus pesadas e indigestas leyes, pero esa literatura no debe ser la nuestra, porque al cortar la cadena enmohecida que nos ligaba a la península, comenzó a tomar otro tinte muy diverso nuestra racionalidad ${ }^{6}$.

Esta búsqueda lírica de un destino propio por medio de la libertad se identifica mucho con

3 RECASENS, Luis. Estudios de filosofía del derecho. Vol. II. México: Uthea, 1946, p. 373 ss.

4 Cf. GARCÍA APONTE, Isaías. Andrés Bello y su contribución al estudio de la historia de las ideas en América. Panamá: Universidad de Panamá, 1964, p. 33.

5 GAOS, José. Introducción a la filosofía del entendimiento de Andrés Bello. México: F.C.E., 1948, pp. LXVII-LXVII.

6 LASTARRIA, José Victorino. Investigaciones sobre la influencia social de la conquista y del sistema colonial de los españoles en Chile. Santiago de Chile: El Siglo, 1984, p. 55. 
los temas planteados por Víctor Hugo y Lamartine, donde la imaginación se hace bélica, heroica y sus únicos fines son la gloria y la patria:

¡Salve bosques que ciñen los verdores postreros!

Amarillos follajes en la hierba esparcidos.

¡Salve, breve hermosura!

La natura enlutada se acomoda al dolor

y me es grata a los ojos ${ }^{7}$.

No se puede negar que la obra poética de Bello, al igual que la filosófica, comenzó con la imitación de las grandes modelos -Virgilio, Horacio, Petrarca, Lope, Garcilazo. Pero lo que realmente la hace novedosa no son los convencionalismos métricos, sino la nueva visión que da a la poesía universal. Es cierto que antes ya se había hecho poesía en la que la tierra exótica del Nuevo Mundo servía como néctar embriagante que excitaba a las musas. Sin embargo, no podemos olvidar que lo que para el poeta extranjero había sido distancia, un mundo onírico, para el americano, en este caso para Bello, fue proximidad y realidad.

Para Bello era indispensable forjar en los jóvenes un cambio a partir de la cultura vista como pilar en la construcción de una sociedad netamente americana. Por medio de su obra poética insiste en la predisposición natural del creador, que ha de inspirarse en su propia realidad. Para nosotros los hispanoamericanos, es un proceso difícil, porque el concepto de realidad siempre ha sido y seguirá siendo caótico. Así lo vio Bello, pero no sólo él. Recordemos un pequeño fragmento del discurso que hace García Márquez en Estocolmo, "La soledad de América Latina”:
Una realidad que no es la del papel, sino que vive con nosotros y determina cada instante de nuestras incontables muertes cotidianas, y que sustenta un manantial de creación insaciable pleno de desdicha y de belleza. Poetas y mendigos, músicos y profetas, guerreros y malandrines, todas las criaturas de aquella realidad desaforada hemos tenido que pedirle muy poco a la imaginación, porque el desafío mayor para nosotros ha sido la insuficiencia de los recursos convencionales para hacer creíble nuestra vida.

Es la belleza y la contradicción de nuestra realidad latinoamericana la que el pensador debe tratar de comprender, y al mismo tiempo expresar; pero ¿cómo aprehender, cómo hacer objeto de estudio esa realidad que transgrede los confines de lo puramente racional? ¿cómo describir una quimera si no es por medio de un poema, un mural, una canción, o una novela? Bello, enamorado de esa realidad que apenas se abría paso para que nos apropiáramos de ella, decidió cambiar los cañones de la guerra por los frutos que la tierra inagotable nos regalaba. Para él la respuesta estaba en la tierra:

¡Oh, jóvenes naciones, que ceñidas alzáis sobre el atónito occidente de tempranos laureles la cabeza!

Honrad al campo, honrad la simple vida del labrador, y su frugal llaneza.

¡Así tendrán en vos perpetuamente, la libertad morada, y freno la ambición, y la ley templo! ${ }^{8}$.

Bello siempre anheló que América comenzara a pertenecer al mundo occidental, no como un elemento adicionado por el descubrimiento, sino como un pilar cultural repre-

LAMARTINE. "El otoño”.

8 Silvas americanas: La agricultura de la zona tórrida, vs. 351-358. 
sentativo, intentando realizar una síntesis entre las formas clásicas europeas y los temas amplios y novedosos que surgen de América.

La idea de una identidad latinoamericana surge en Bello debido a la reacción pusilánime que toma Europa frente a nuestras manifestaciones culturales: América se levantará como la promesa de una tierra "al hombre sometida apenas” (vs. 168-88). Y así, dando muestra de la riqueza americana, inserta en su obra un espíritu libre de vergüenza, convencido del valor de su tierra; en otras palabras, lleno de amor por la patria y de orgullo de ser latinoamericano.

¡Salve fecunda zona, que al sol enamorado circunscribes el vago curso,

y cuanto ser se anima en cada vario clima

acariciada de su luz concibes tú tejes al verano su guirnalda de granadas espigas! ${ }^{9}$.
La “Alocución a la poesía” y "La agricultura de la zona tórrida”, fueron consideradas como las primeras proclamas de la independencia intelectual de nuestra América. Su aspecto descriptivo desencadenó una corriente de poetas regionalistas que aún son citados en los epígrafes de los panfletos que aluden a una nueva liberación por medio de las granadas. Hoy el frente de las embajadas cada vez se congestiona más, intentamos huir, pero no se nos puede condenar, porque si Adán y Eva, aconsejados por el propio Dios, lo hicieron, nosotros también podemos cerrar los ojos ante lo evidente y salir del paraíso sin mayores remordimientos.

El mensaje de Bello sigue allí, en sus poesías, pero es de nuestras acciones, en las que construimos cultura e identidad latinoamericana, que depende su vigencia.

Bello nos demuestra que para ser un verdadero pensador no es necesario escribir textos filosóficos extravagantes, sólo transmitir los ecos inaudibles de la tierra.

9 Ibíd., vs. 1-4. 